\title{
Narrative review of the choices of stem cell sources and hydrogels for cartilage tissue engineering
}

\author{
Zhantao Deng ${ }^{1 \#}$, Jiewen Jin ${ }^{2 \#}$, Shuai Wang ${ }^{1}$, Fangjie Qi ${ }^{1}$, Xuepan Chen ${ }^{1}$, Chang Liu ${ }^{1}$, Yanbing Li $^{2}$, \\ Yuanchen $\mathrm{Ma}^{1}$, Fengjuan Lyu ${ }^{1,3}$, Qiujian Zheng ${ }^{1}$ \\ ${ }^{1}$ Department of Orthopedics, Guangdong Provincial People’s Hospital, Guangdong Academy of Medical Sciences, Guangzhou, China; ${ }^{2}$ Department \\ of Endocrinology, The First Affiliated Hospital, Sun Yat-sen University, Guangzhou, China; ${ }^{3}$ South China University of Technology-the University \\ of Western Australia Joint Center for Regenerative Medicine Research, School of Medicine, South China University of Technology, Guangzhou, \\ China \\ Contributions: (I) Conception and design: Z Deng, J Jin, Y Ma, F Lyu, Q Zheng; (II) Administrative support: F Lyu, Q Zheng; (III) Provision of study \\ materials or patients: None; (IV) Collection and assembly of data: Z Deng, J Jin, S Wang, F Qi, X Chen, C Liu; (III) Data analysis and interpretation: \\ Y Li, Y Ma, F Lyu, Q Zheng; (IV) Manuscript writing: All authors; (V) Final approval of manuscript: All authors. \\ \#These authors contributed equally to this work. \\ Correspondence to: Dr. Qiujian Zheng; Dr. Fengjuan Lyu. Department of Orthopedics, Guangdong Provincial People's Hospital, Guangdong Academy \\ of Medical Sciences; School of Medicine, South China University of Technology, No. 106, Zhongshan Second Road, Yuexiu District, Guangzhou, \\ China. Email: zhengqiujian@gdph.org.cn; Lufj0@scut.edu.cn.
}

\begin{abstract}
Stem cell-based therapy is a promising treatment for cartilage defects due to the pluripotency, abundant sources and low immunogenicity of stem cells. Hydrogels are a promising class of biomaterials for cartilage engineering and are characterized by bioactivity, degradability and elasticity as well as provide water content and mechanical support. The combination of stem cells and hydrogels opens new possibilities for cartilage tissue engineering. However, the selection of suitable types of stem cells and hydrogels is difficult. Currently, various types of stem cells, such as embryonic stem cells (ESCs), mesenchymal stem cells (MSCs), induced pluripotent stem cells (iPSCs), and peripheral blood mononuclear cells (PBMSCs), and various types of hydrogels, including natural polymers, chemically modified natural polymers and synthetic polymers, have been explored based on their potential for cartilage tissue engineering. These materials are used independently or in combination; however, there is no clear understanding of their merits and disadvantages with regard to their suitability for cartilage repair. In this article, we aim to review recent progress in the use of stem cell-hydrogel hybrid constructs for cartilage tissue engineering. We focus on the effects of stem cell types and hydrogel types on efficient chondrogenesis from cellular, preclinical and clinical perspectives. We compare and analyze the advantages and disadvantages of these cells and hydrogels with the hope of increasing discussion of their suitability for cartilage repair and present our perspective on their use for the improvement of physical and biological properties for cartilage tissue engineering.
\end{abstract}

Keywords: Stem cells; hydrogels; cartilage tissue engineering

Submitted Mar 09, 2020. Accepted for publication Sep 24, 2020.

doi: $10.21037 / \mathrm{atm}-20-2342$

View this article at: http://dx.doi.org/10.21037/atm-20-2342

\section{Introduction}

Cartilage-related tissue defects are a common cause of disability and account for $6 \%$ of disabled people over 30 years of age (1). Cartilage defects are a major problem in orthopedic surgery and are commonly caused by traumatic injury, disease and aging. Persistent cartilage injury may induce irrevocable deterioration of joints, leading to osteoarthritis and disabilities (2). Due to the absence of vascularization, nutrient supply and proper endogenous 
progenitor cells, the self-repair capability of cartilage is quite limited.

Traditional treatments for cartilage-related tissue defects include microfracture surgery or autologous chondrocyte implantation. Despite the common use of traditional treatments in clinical practice, they have notable shortcomings that cannot be neglected. Microfracture may induce cartilage regeneration by drilling tiny holes that penetrate the cartilage and subchondral bone to bring stem cells and biomolecules to the defects. However, microfracture frequently leads to the formation of fibrocartilage, which has inferior biofunctions compared to articular cartilage $(3,4)$. Autologous chondrocyte implantation has a satisfactory surgical outcome and has been used clinically for two decades. Nevertheless, due to the long harvest time of autologous chondrocytes, the shortage of chondrocyte sources and their low effectiveness in aged patients, additional surgery may be required, and the possibility of donor morbidity has to be considered (5).

Cartilage tissue engineering has been proposed as a more effective treatment, which can be achieved by two main approaches. One approach is to mimic the architectural features and biological functions of native cartilage by regenerating articular cartilage, osteochondral interface tissues and zonal structures into a highly complex composition using advanced manufacturing technology. Another approach is to deliver appropriate biomaterials as an artificial extracellular matrix (ECM) to facilitate cell growth, proliferation, and differentiation at the sites of the defects, thus leaving the regeneration of the articular cartilage and subchondral bone to native biological processes (6).

Hydrogels are versatile biomaterials used in cartilage tissue engineering due to their unique properties, which are similar to the characteristics of natural ECMs. The structure, composition, and biochemical and mechanical properties of hydrogels are conveniently tunable to suit various desired applications (7). Hydrogels can serve as ECMs to control cell morphology, proliferation, and differentiation at a defect site $(8,9)$. Moreover, cell-laden hydrogels can be manufactured by advanced techniques with patient-customized compositions $(10,11)$. Hence, it is widely accepted that hydrogels loaded with cells and growth factors have great potential to address the challenge of regenerating full-thickness cartilage (9). In the literature, chondrocytes embedded in various types of hydrogels have demonstrated a well-maintained cell phenotype (12). However, the application of chondrocytes has certain limitations. First, chondrocytes are harvested from healthy cartilage tissue at a non-weight-bearing site, which may lead to morbidity of the donor site. Second, the number of chondrocytes is limited and it takes as long as 3 to 5 weeks for the in vitro expansion of cells. Third, the proliferation capacity of chondrocytes is low, especially in the case of chondrocytes derived from aged patients.

Thus, stem cell-based therapy is considered to be a more promising approach to treat cartilage defects because of its strong chondrogenic potential and proliferative capacity. Different types of stem cells are suitable for cartilage engineering with easy access, such as mesenchymal stem cells (MSCs), induced pluripotent stem cells (iPSCs), embryonic stem cells (ESCs), and peripheral blood mononuclear cells (PBMSCs). MSCs are the most widely used stem cells; they are derived from a variety of sources (such as bone marrow, adipose tissue and muscle) and can proliferate without differentiation for up to 40 generations. MSCs can interact with local biochemical stimuli and generate a number of growth factors for tissue restoration. The use of ESCs and iPSCs is emerging in cartilage engineering due to their pluripotency and potential to differentiate into almost all cell lineages, including chondrogenic lineages.

In this review, we will briefly revisit the hydrogels explored in cartilage repair, focus on the recent advances in the utilization of stem cells combined with hydrogels for cartilage repair and discuss the advantages and disadvantages of various options in the hope that we can shed light on these topics for future studies and for the clinical development of stem cells and biomaterial-based cartilage regeneration. We present the following article in accordance with the Narrative Review reporting checklist (available at http://dx.doi.org/10.21037/atm-20-2342).

\section{Methods used for the literature search}

This systematic research was performed using the Web of Science and PubMed databases with the following search string: "stem cell" OR "mesenchymal stem cells" OR "embryonic stem cells" OR "induced pluripotent stem cells" OR "peripheral blood mononuclear cells" AND "hydrogel" OR "hyaluronic acid" OR "chitosan" OR "alginate" OR "agarose” AND “cartilage repair" OR "cartilage rehabilitation". Papers published in English up to April 2019 were selected. 


\section{Results of the literature search}

The results of the literature search are shown in Figure 1. The initial search resulted in 1,497 articles. After exclusion of duplicates, 644 articles remained, which were then subjected to a manual review based on their titles and abstracts. A total of 274 articles were reviews, editorial or conference presentations, and 138 papers were not related

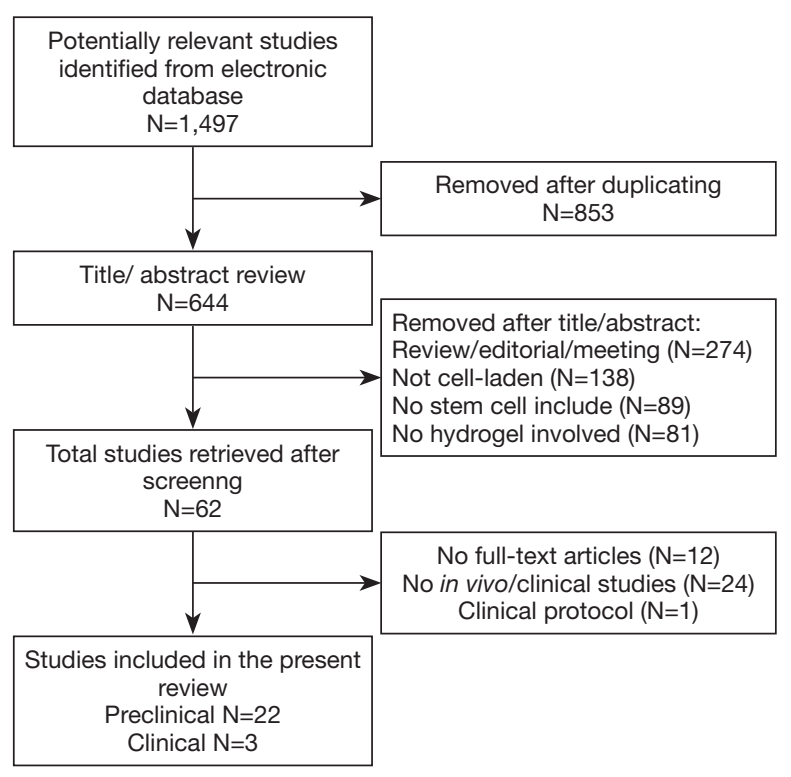

Figure 1 Flowchart of literature search. to stem cells. Out of the remaining articles, 89 papers were irrelevant to stem cells and 81 papers did not involve hydrogels. Thus, 62 studies remained after screening. We further excluded 12 articles without an available full-text, 24 studies without in vivo observations, and a clinical study that did not specify the clinical protocol. Finally, 22 preclinical studies and 3 clinical studies were included in the present review.

\section{Hydrogels for cartilage reconstruction}

Hydrogels are a series of ECM-mimicking polymeric biomaterials that have a high water content, porosity, biocompatibility and biodegradability. As shown in Figure 2, hydrogels are injectable, which is a minimally invasive method unlike implantation surgery, and can be formed into any desired shape to match irregular defects $(13,14)$. During the past decade, a rich variety of hydrogels have been developed from natural polymers, chemically modified natural polymers, or synthetic polymers or have been used in combination for regeneration of cartilage tissues. Hydrogels based on natural polymers can be divided into two groups: (I) polysaccharides, such as hyaluronic acid (HA), chitosan, alginate and agarose; (II) proteins, such as collagen, gelatin, and fibroin (15-20). A variety of hydrogels based on synthetic polymers, such as polyethylene glycol (PEG), poly N,N-dimethylacrylamide (PDMAAm) and polyvinyl alcohol (PVA), have been reported (21-23).

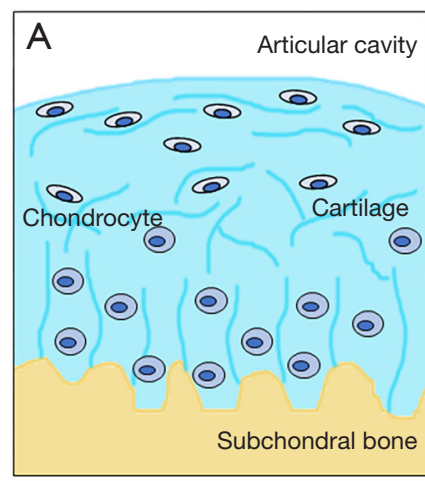

Normal cartilage

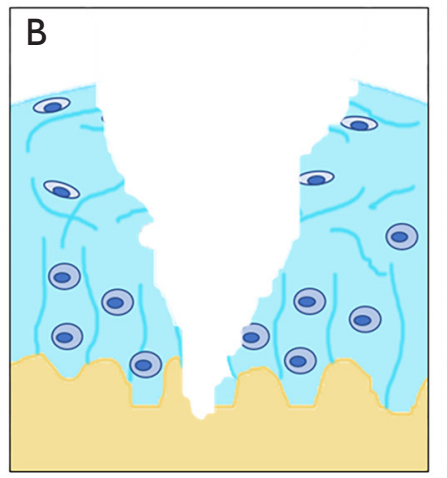

Cartilage defect

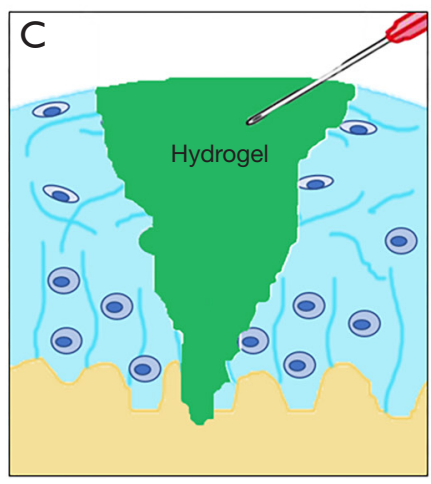

Hydrogel injection

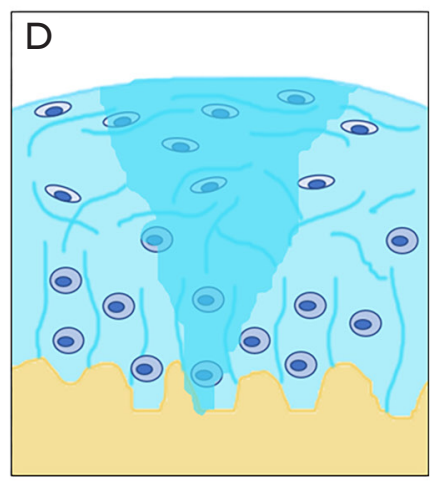

Cartilage regeneration

Figure 2 Ideograph of cartilage repair by hydrogels. (A) The composition of normal cartilage, including well organized cartilage, chondrocytes in cartilage and the supporting subchondral bone; (B) in various diseases, cartilage is impaired, including the layer of cartilage and the subchondral bone, which is often irregular; (C) the injection of a hydrogel by an injection syringe is a minimally invasive method that can form any desired shape to match irregular defects; (D) regeneration of the cartilage by reconstruction of the cartilage layer and the subchondral bone. 


\section{Page 4 of 19}

Furthermore, natural and synthetic polymers can be fabricated into combinations, which provide additional possibilities for selection.

\section{HA bydrogels}

HA is the most abundant native component in cartilage and an important component in organizing the cartilage $\mathrm{ECM}$ into resilient structures. HA is able to interact with chondrocytes via surface receptors (such as RHAMM and CD44) (14), which contributes to the morphogenesis, proliferation, and inflammation activity of chondrocytes and has stimulatory effects on the chondrocyte metabolism (24). HA is also able to stimulate the synthesis of chondroitin6-sulphate, collagen type II, glycosaminoglycan, hydroxyproline, and DNA in chondrocytes. Hence, an effort has been made to develop chondrocyte-laden HA hydrogels for the regeneration of cartilage tissues $(25,26)$. HA hydrogels have been demonstrated to support the early differentiation of MSCs into the chondrogenic linage and enhance cartilage tissue formation in vitro and in vivo $(27,28)$. MSC-laden HA hydrogels can promote neocartilage formation with increased collagen type II and aggrecan production (29). However, HA hydrogels have certain disadvantages. The mechanical properties of HA hydrogels are poor. HA is easily hydrolyzed and rapidly degraded at body temperature, which limits its applications. To overcome these drawbacks, a series of modifications have been developed. Chemical modifications of HA can be achieved via reacting its carboxylic groups with various hydroxyl- or amine-bearing motifs to form derivatives with improved biocompatibility and controlled biodegradability (30). Conjugation with tunable amounts of sulfate groups produces HA hydrogels with significantly slower degradation by hyaluronidase and improved protein sequestration compared to unmodified HA hydrogels, thus promoting chondrogenesis and suppressing the hypertrophy of encapsulated MSCs both in vitro and in vivo (16). Reactions with the hydrazine-modified elastin-like protein can produce elastin-like protein-HA hydrogels, which can increase the expression of chondrogenic marker genes and enhance soluble sulfated glycosaminoglycan (sGAG) deposition while minimizing the undesirable fibrocartilage phenotype (31).

\section{Alginate bydrogels}

Alginate is a polysaccharide extracted from brown algae

\section{Deng et al. Stem cell and hydrogels for cartilage reconstruction}

and can be physically crosslinked by divalent cations at room temperature, which makes it useful in molding, spraying, and 3D bioprinting (32). Alginate hydrogels are characterized by favorable scaffold formation, high biocompatibility, low toxicity, lack of immunogenicity and relatively low cost $(33,34)$. Cartilage engineering using bone marrow-derived MSCs (BMSCs) suspended in alginate hydrogels can enhance the regeneration of chondral defects and promote mechanically functional repair tissue (35) while exhibiting negligible inflammatory and oxidative stress responses. Furthermore, a recent study revealed that the development of MSC-laden alginate hydrogels that mimic the effects of hypoxia on encapsulated stem cells results in a more stable, cartilagelike tissue (36). However, alginate hydrogels have certain limitations for tissue engineering. First, alginate hydrogels lack long-term stability and have low mechanical strength in the physiological environment within a relatively short timeframe. Second, alginate hydrogels have low cellular adhesiveness and interaction and provide limited support for cellular functions (37). Therefore, alginate is often used in a modified form, such as with a sulfate modification, or is combined with other materials, which can facilitate cell spreading, proliferation, and collagen II synthesis and render the material more suitable for $3 \mathrm{D}$ printing (38).

\section{Agarose bydrogels}

Agarose is a type of polysaccharide that forms thermally reversible hydrogels at $17-40{ }^{\circ} \mathrm{C}$ and is soluble at temperatures over $65^{\circ} \mathrm{C}(37)$. The strengths of agarose hydrogels include their stability at body temperature and lack of native ligands for cell-material interactions. Additionally, agarose hydrogels have excellent biocompatibility, stiffness and viscoelasticity. A number of studies have demonstrated that agarose hydrogels promote chondrocyte phenotype maintenance in cartilage regeneration $(39,40)$. Agarose hydrogels can support chondrogenic differentiation and cartilaginous tissue formation by the encapsulated MSCs (41). The temperature-responsive gelation ability of agarose hydrogels enables the design of injectable cell-laden hydrogels for minimally invasive treatment of cartilage defects (42). However, compared with other hydrogels (such as collagen and alginate), agarose hydrogels are inadequate in supporting ECM generation, chondrocyte proliferation and cell phenotype maintenance $(43,44)$. 


\section{Chitosan bydrogels}

Chitosan is derived from chitin, the second most abundant natural biopolymer from renewable sources, such as crustacean shells and mushrooms envelopes (45). Chitosan and cartilage glycosaminoglycan have similar structures that are biodegradable and biocompatible. Chitosan hydrogels prepared by enzymatic crosslinking can support proliferation, maintain the chondrogenic phenotype and morphology, and boost the deposition of the cartilaginous ECM of chondrocytes and MSCs in vitro (46,47). Longterm in vitro culture and in vivo subcutaneous implantation of MSC-laden chitosan hydrogels demonstrates their ability to support chondrogenesis and hypertrophy of MSCs (41). However, the preparation of chitosan is complex since it is insoluble in water and has to be dissolved in an acetic acid solution, which requires tedious washing steps. Recently, water soluble chitosan has been introduced and characterized as having limited water uptake, shorter gelation times and tighter hydrogel structures (48).

\section{Collagen/Gelatin hydrogels}

Collagen is the most abundant native structural protein component of the ECM. Collagen II is the major type of collagen in cartilage. Collagen has been widely used in tissue engineering because of its weak antigenicity and high compatibility with other biomaterials. Collagen is able to maintain the natural morphology and secretion of the cartilage-specific ECM of chondrocytes (49). Collagen II hydrogels have been shown to have the best ability of all collagen types to induce and maintain MSC chondrogenic differentiation in the absence of transforming growth factor (TGF)- $\beta 1$ (50). Collagen can support the formation of microspheres by MSC due to its fibrous meshwork, which provides a good environment for MSC survival, growth and differentiation (51).

Gelatin is a hydrolyzed product derived from collagen and is the major ECM component in cartilage tissue. Gelatin has excellent cell adhesion, high biocompatibility and biodegradability. However, it has a drawback: the low stability of its physical crosslinks at body temperature. Therefore, chemical modification of gelatin hydrogels is required before they can be used in tissue engineering (52). Methacryloyl-modified gelatin (GelMA) retains most of the functional amino acid motifs, thus inheriting the excellent cell adhesive properties of gelatin. MSC-laden GelMA hydrogels have been demonstrated to be able to stimulate abundant production of aggrecan and type II collagen in vitro (53).

\section{Silk fibroin hydrogels}

Silk fibroin is a novel type of biomaterial used in tissue engineering and has excellent biocompatibility, robust mechanical properties, slow degradability and an abundant supply. A cellular study revealed that chondrocyte/MSCladen fibroin hydrogels have the abundant native cartilagelike ECM of aggrecan and collagen type II (54); therefore, silk fibroin is a suitable candidate type for hydrogel generation for cartilage tissue engineering. However, studies have suggested that MSCs produce lower levels of cartilage ECM when loaded on fibroin hydrogels compared with the properties achieved in the case of alginate and chitosan hydrogels (41), indicating the lower potential of fibroin hydrogels for cartilage repair. Additional studies on silk fibroin are required before a conclusion can be drawn about its potential for cartilage repair.

\section{Synthetic polymers-based hydrogels}

Hydrogels based on synthetic polymers exhibit highly tunable biocompatibility, biodegradability, biochemical characteristics and mechanical properties. PEG-based hydrogels in combination with organic growth factors support the adhesion and proliferation of MSCs, ESCs and chondrocytes, which can differentiate into chondrogenic linages (55). PEG diacrylate (PEGDA)-based hydrogels have been widely studied for their ability to induce cartilage regeneration. PEGDA hydrogels loaded with MSCs can facilitate improved cartilage ECM deposition, adjacent cartilage tissue growth, and cartilage tissue formation compared to the standard microfracture treatment (56). The PEGDA/fibrinogen composite hydrogel has been shown to enhance chondrogenesis of MSCs while minimizing hypertrophic differentiation (57), which suggests that composite hydrogels can be designed to improve cartilage tissue regeneration. Thermosensitive chitosan-pluronic (CP) hydrogels have been synthesized by grafting pluronic onto chitosan. CP hydrogels are soluble at room temperature but turn semisolid at body temperature; thus, CP hydrogels can be delivered by injection while providing mechanical support for chondrocyte growth (46). Fibrin/ PLGA hydrogels loaded with MSCs have been designed for full-thickness cartilage defect repair (58). However, 
Table 1 Merits and demerits of different types of hydrogels

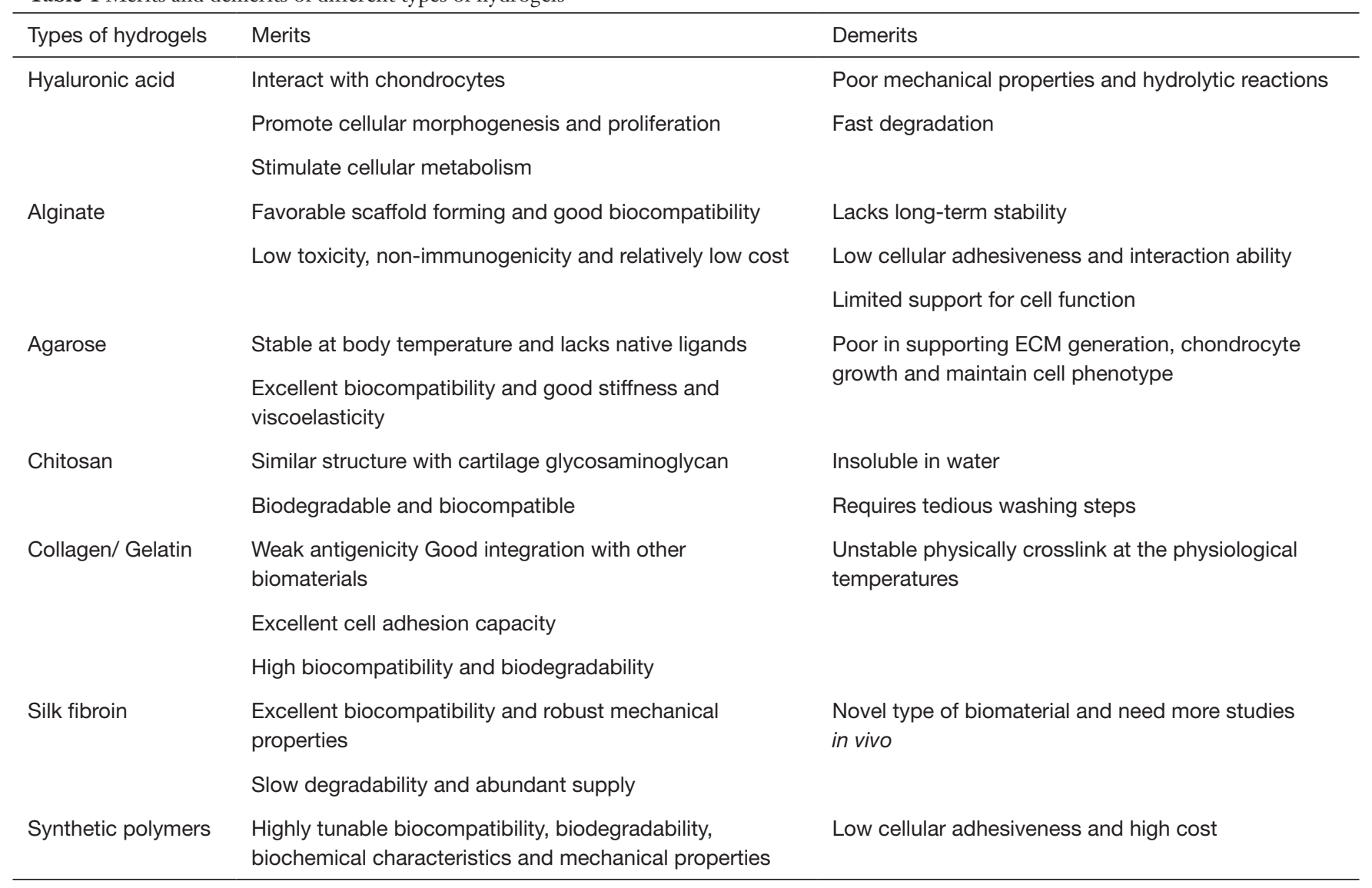

hydrogels based on synthetic polymers have the common disadvantages of relatively low cellular adhesiveness and high cost compared to natural polymer hydrogels.

\section{Choice of hydrogels for cartilage engineering?}

We compared and summarized the merits and disadvantages of the discussed hydrogels in Table 1. In the analyzed list of the hydrogels, alginate is not suitable due to its shortterm stability and low cellular adhesiveness; additional work needs to be performed before synthetic polymersbased hydrogels can be applied in the clinic. HA, agarose and collagen may be more suitable than alginate and can be improved via chemical modifications to enhance their biocompatibility and controlled biodegradability. Silk fibroin is a new player in the field and is very promising. However, there are only a few studies on silk fibroin, and additional work is required to establish its potential in vivo. Compared to the limited number of types of natural hydrogels, synthesized polymers have substantially higher variability, and this category is continuously expanding. In general, natural hydrogels have higher biocompatibility and cell viability than chemically modified and synthetic hydrogels, while chemically modified and synthetic hydrogels have widely tunable mechanical properties and suitable biodegradability for effective cartilage regeneration and clinical translation.

A few studies have performed comparative analyses of the cartilage regeneration effects of various hydrogels. A 2019 study compared the effects of various polysaccharides-gellan gum (GG), alginate, agarose and HA hydrogels on cartilage regeneration in vitro and in vivo and found that all the hydrogels, except alginate, resulted in tissue regeneration, while the effects of GG and agarose were better (59).

\section{Chondrogenesis of stem cells encapsulated in hydrogels}

Stem cells can differentiate into various tissue-forming cells, including chondrogenic and osteogenic lineages for cartilage 
and bone regeneration. The most commonly studied stem cells include MSCs, iPSCs, ESCs, and PBMSCs. Here, we review recent advances in the application of various stem cells for the repair of the cartilage defects.

\section{MSCs: extensively used and targeted reconstruction}

MSCs have become the most extensively used stem cells in regenerative medicine because their sources are abundant (such as bone morrow, adipose tissue, muscle, periodontal ligament and synovial fluid); MSCs have low immunogenicity, no ethical concerns, and a minimal teratoma risk (60). MSCs are able to proliferate without differentiation for up to 40 generations (61) and interact with local biochemical stimuli to generate a number of growth factors that provide multiple biofunctions for tissue restoration (60). MSCs can be derived from a variety of sources, including bone morrow, adipose tissue, muscle, periodontal ligament, synovial fluid, etc.; the various MSCs differ in their surface marker expression, growth factor secretion and differentiation potential. MSCs derived from birth-associated neonatal tissues, including the umbilical cord, placenta, amnion, and cord blood, have a better proliferative capacity, higher availability, longer life span, and higher differentiation potential than MSCs obtained from distinct mature adult tissues of adipose, muscle, and bone origin (62). MSCs encapsulated in various hydrogels have been tested to target the reconstruction of cartilage tissues in preclinical and clinical settings (35,63-87) (Tables 2,3). Various hydrogels exhibit variable abilities to support chondrogenesis and osteogenesis of MSCs. MSCs encapsulated in collagen hydrogels show enhanced in vitro formation of osteochondral interface tissues with a zonal structure consisting of a pure cartilage layer, a calcified cartilage layer, and a subchondral bone layer (88). The results of this study suggested that MSC-laden hydrogels can be promising biomaterials for osteochondral interface regeneration.

\section{Bone marrow-derived MSCs (BMSCs)}

BMSCs are the most commonly used stem cells in cartilage tissue engineering (Table 2). BMSCs have been used for injection with hydrogels in focal defects to promote cartilage repair in rats (75), rabbits (76), goats (87), pigs (80), and donkeys (83). Thirteen published preclinical studies compared the use of BMSCs in combination with hydrogels, and 12 studies demonstrated the benefits of using BMSC-laden hydrogels to decrease inflammation and apoptosis (77), increase their integration with healthy cartilage in the superficial and inner parts (83) and improve cartilage healing (86). Only a single study described better results in counteracting progression of osteoarthritis using MSCs and HA separately compared with the effects of their combination (79). Furthermore, a comparative clinical study $(\mathrm{N}=70)$ explored the efficacy of BMSC-laden HA hydrogels compared with traditional microfracture treatment. There was a significant improvement in the mean IKDC, Lysholm, and SF-36 physical component score and the visual analogue pain scores in both treatment groups without significant differences between groups (81).

A series of modification by scaffolds have been developed to improve the biofunctions of BMSCs in tissue restoration. Pre-encapsulation of bone morphogenetic protein-2 (BMP-2) in PLGA microspheres resulted in controlled release of BMP-2; the formulation was safe, easily injectable, and provided better support for cells in the BMSC-laden hydrogels (64). The incorporation of HA and PDLLA-PEG hydrogels allowed for the slow release of one-time preloaded TGF- $\beta 3$, which resulted in constructs with a significantly higher mechanical strength than the conventional TGF- $\beta 3$-supplemented medium loaded with BMSCs and cultured in vitro (89). Hypoxia can control the fate of stem cells after their implantation into the body. The delivery of DMOG, hypoxia-inducible factor (HIF) and prolyl hydroxylase inhibitors that mimic hypoxia in the microenvironment significantly reduced the mineralization of cartilaginous tissue generated by BMSCs within alginate hydrogels loaded with BMP-2 and TGF- $\beta 3$ (36). Platelet lysate is an autologous source of growth factors that can be incorporated into a MSCladen HA-TA hydrogels to induce a cartilage-like ECM deposition simultaneously with gel degradation, ultimately resulting in the formation of a tough and dense matrix (11). The addition of peptides or heterocyclic compound, such as transmembrane glycoprotein $\mathrm{N}$-cadherin-derived peptides (90), icariin (91) and kartogenin (92), increases the chondrogenesis of encapsulated BMSCs in the early stages and enhances cartilage matrix production. Furthermore, new hydrogel materials, such as magnetic nanocomposites, have good mechanical properties and can provide a surface for the uniform growth of BMSCs, resulting in high rates of proliferation. Additionally, supplementation with $\mathrm{Fe}_{2} \mathrm{O}_{3}$ can enhance BMSC growth and significantly stimulate chondrocyte-related gene expression in BMSCs (93). 


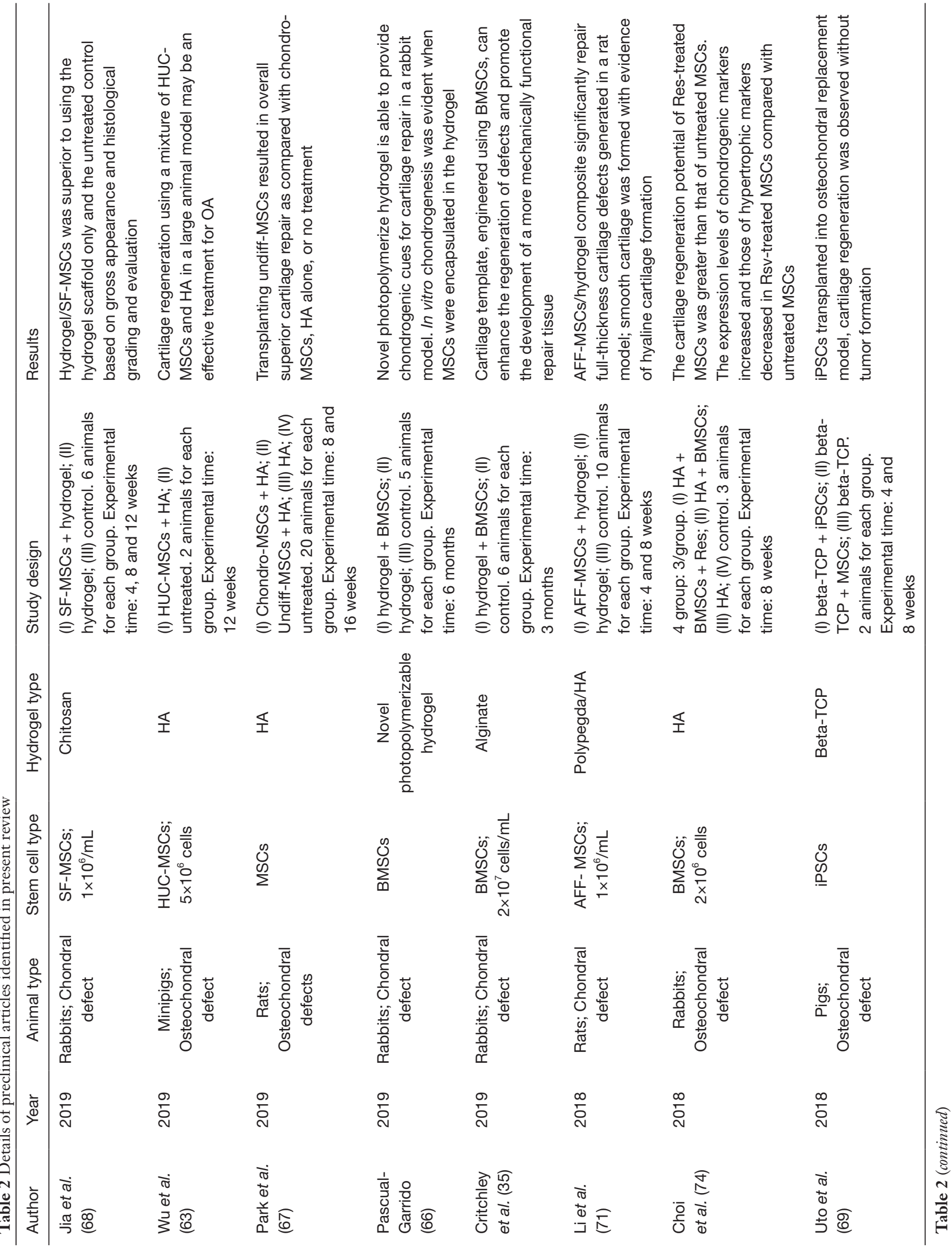




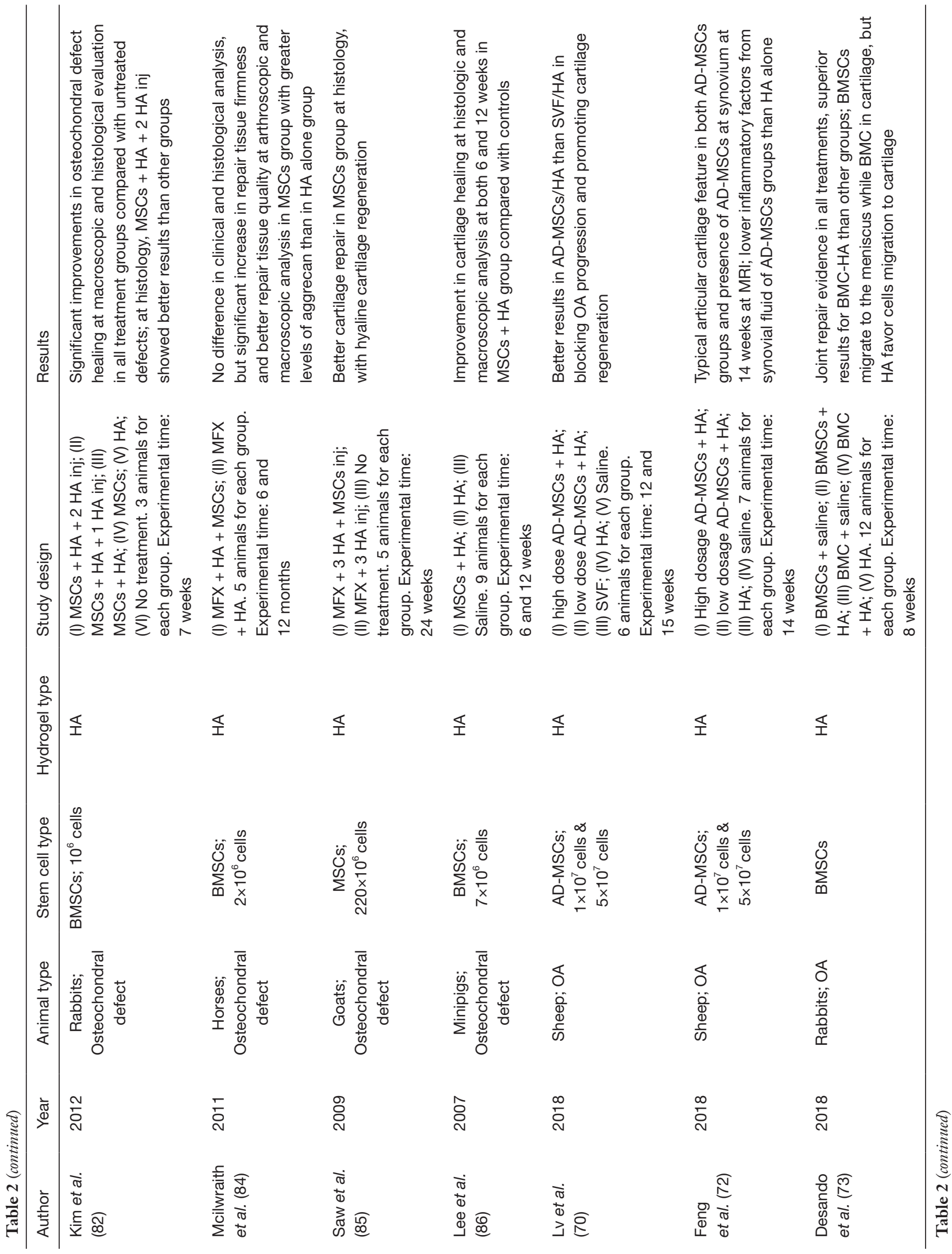




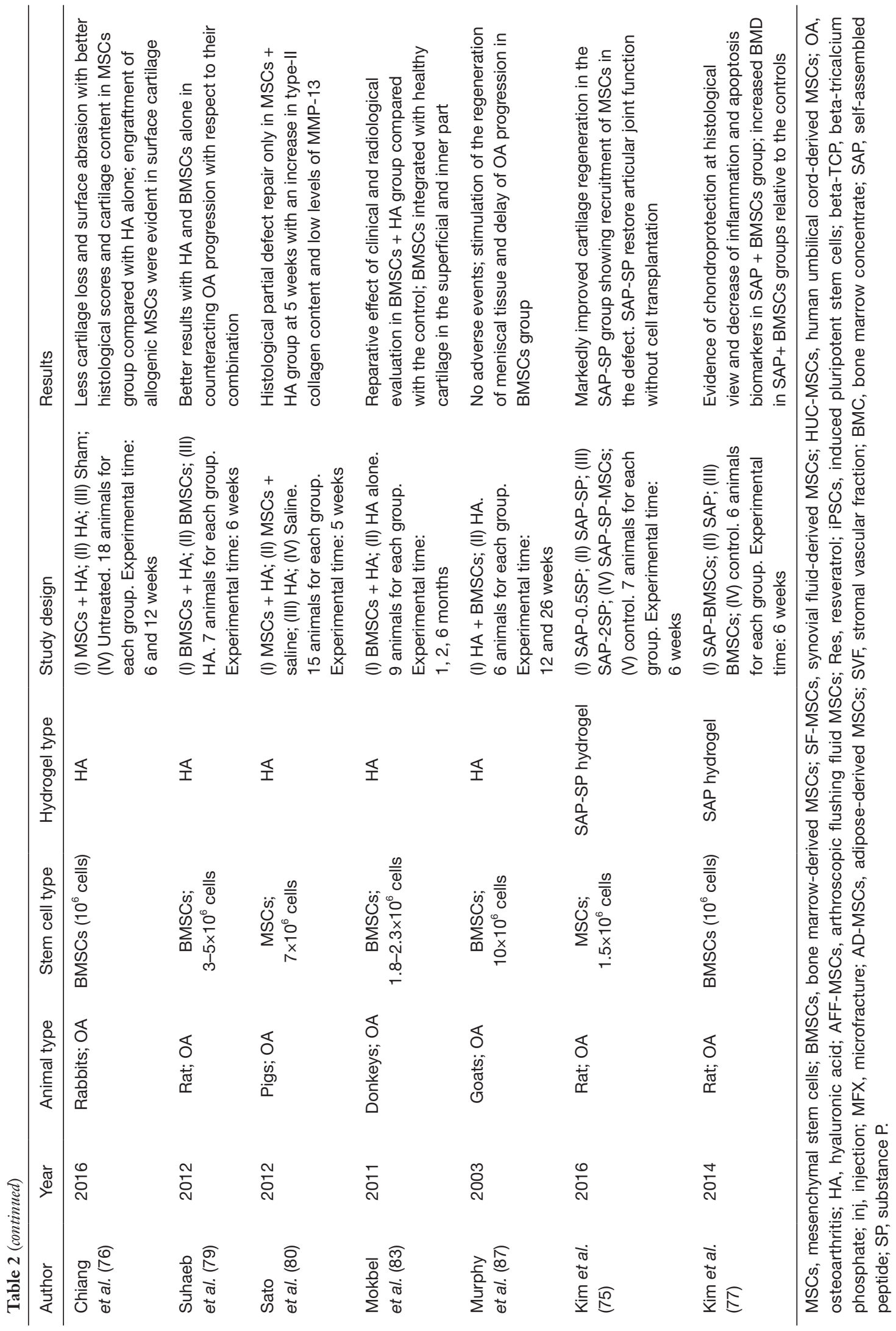


Table 3 Details of clinical articles identified in present review

\begin{tabular}{|c|c|c|c|c|c|c|c|}
\hline Author & Year & Study type & Defect type & $\begin{array}{l}\text { Stem cell } \\
\text { type }\end{array}$ & $\begin{array}{l}\text { Hydrogel } \\
\text { type }\end{array}$ & Study design & Results \\
\hline $\begin{array}{l}\text { Pipino } \\
\text { et al. } \\
(65)\end{array}$ & 2019 & Comparative & $\begin{array}{c}\text { Osteochondral } \\
\text { defect }\end{array}$ & AD-MSCs & PG/GC & $\begin{array}{l}\text { Lesion size: Outerbridge III- } \\
\text { IV. Groups [2]: (I) MFX + AD- } \\
\text { MSC ( } n=46) ;(\text { II) MFX ( } n=23) \text {. } \\
\text { Follow-up: } 6,12 \text { and } \\
24 \text { months }\end{array}$ & $\begin{array}{l}\text { Patient has high satisfaction } \\
\text { rates after microfractures } \\
\text { combined with hydrogel } \\
\text { scaffold; histologic evaluation } \\
\text { supported an enhanced } \\
\text { chondrogenic environment in } \\
\text { combined group }\end{array}$ \\
\hline $\begin{array}{l}\text { Saw } \\
\text { et al. } \\
\text { (78) }\end{array}$ & 2013 & RCT & $\begin{array}{l}\text { Chondral } \\
\text { lesion }\end{array}$ & PBMCs & $\mathrm{HA}$ & $\begin{array}{l}\text { Number: } 50 \text {. Lesions size: } \\
\text { ICRS grade } 3 \text { and } 4 \text { lesions. } \\
\text { Groups [2]: (I) PBPCs + HA; } \\
\text { (II) HA. Follow-up: from } \\
18 \text { to } 24 \text { months }\end{array}$ & $\begin{array}{l}\text { Improvement of the quality of } \\
\text { articular cartilage repair in PBSC } \\
\text { group at histologic and MRI } \\
\text { evaluation }\end{array}$ \\
\hline
\end{tabular}

AD-MSCs, adipose-derived MSCs; PG/GC, polyglucosamine/glucosamine carbonate; MFX, microfracture; RCT, Randomized controlled trial; PBMCs, peripheral blood mononuclear cells; HA, hyaluronic acid; BMSCs, bone marrow-derived MSCs.

\section{Adipose-derived MSCs (AD-MSCs)}

AD-MSCs are the second most commonly used stem cells in cartilage tissue engineering, which can be isolated in high numbers with minimal manipulation even in the operation theatre and can be expanded in vitro without loss of their chondrogenic potential (94). In two preclinical studies, the AD-MSC-laden group had low levels of inflammatory factors from synovial fluid, blocked progression of osteoarthritis and promoted cartilage regeneration $(70,72)$. Culturing $\mathrm{AD}-\mathrm{MSCs}$ in a composite gel based on collagen/HA leads to chondrogenic differentiation of AD-MSCs stimulated by the collagen hydrogel in a dose dependent manner, with $1 \%$ HA showing the best results (94). Recently, a comparative clinical study investigated microfracture combined with a novel hydrogel (polyglucosamine/glucosamine carbonate) laden with AD-MSCs and compared the results with the effect of microfracture alone. Higher patient satisfaction rates were reported in the microfracture combined with the novel hydrogel scaffold group, while histologic evaluation supported the improvement in the chondrogenic environment in the combination group (65).

\section{MSCs derived from other sources}

Other sources of MSCs investigated for cartilage repair include synovial fluid-derived MSCs (SF-MSCs), arthroscopic flushing fluid-derived MSCs (AFF-MSCs), and umbilical cord-derived MSCs (UC-MSCs). Hydrogel laden with SF-MSCs was superior in regard to gross improvement, histological grade and evaluation compared with the effects of the hydrogel scaffold only or the untreated control in full-thickness cartilage defects in rabbits (68). Moreover, supplementation of transforming growth factor beta-3 (TGF- $\beta 3$ ) and insulin-like growth factor 1 (IGF-1) promoted the differentiation of SFMSCs into chondrocytes (95). Several clinical studies have reported that SF-MSCs are a viable option for the treatment of osteochondral defects, while the donor-todonor variation should be considered and can significantly influence downstream applications (96-98). AFF-MSCs possess the typical MSC morphology and phenotype, and their encapsulation within the one-step rapid crosslinking hyper-branched polyPEGDA/HA hydrogel results in maintenance of the chondrogenic differentiation potential in vitro (71). AFF-MSCs lead to the repair of full-thickness cartilage defects with the formation of new hyaline cartilage 
in a rat model after eight weeks of implantation (71). Similarly, a combination of human UC-MSCs and HA has been shown to be an effective treatment for osteoarthritis in a pig model (63). The composition of UC-MSCs and HA has been demonstrated to significantly improve the visual analog scale (VAS) and IKDC scores in a clinical study, which were maintained for up to 7 years at follow-up (99).

\section{ESCs: pluripotent but it is hard to direct their differentiation}

ESCs are isolated from the inner tissues of early embryos and have the potential to differentiate into almost all cell lineages in the human body (100). A study has indicated that ESCs encapsulated in PEG hydrogels can differentiate into chondrocytes and produce the neocartilage ECM (101). Recent studies have revealed that exosomes from ESCs are able to alleviate osteoarthritis by balancing the synthesis and degradation of the cartilage extracellular matrix to promote osteochondral regeneration $(102,103)$. However, the pluripotency of ESCs is problematic because the direction of ESC differentiation is difficult to control (104). In addition, ESCs have the risk of immune rejection and ethical concerns (105). Therefore, ESCs are not a suitable choice for cartilage engineering; however, exosomes from ESCs are a potential new target of OA therapy.

\section{iPSCs: newly developed and promising}

iPSCs are obtained from somatic cells, including fibroblasts. iPSCs exhibit a similar pluripotency as ESCs and have the ability to differentiate into chondrocytes in alginate hydrogels and regenerate cartilage tissues in vivo (106). In a porcine model, iPSCs transplanted into osteochondral defects regenerated cartilage without tumor formation (69). iPSCs can be induced to undergo chondrogenic differentiation on a 3D micro-cavitary hydrogel interim platform. iPSCs can generate a graft, with cells exhibiting a chondrocyte phenotype with abundant and assembled type II collagen (107). Moreover, chondroinduced iPSCs show a significantly higher level of cartilage repair than chondroinduced BMSCs due to the significantly higher methylation of $\mathrm{CpG}$ sites in the COL10A1 promoter; the induced cells have a low hypertrophy of chondrocytes and improve cartilage repair (106). Hence, iPSCs emerge as a promising cell source for the treatment of the cartilage defects and have potential for clinical application. Additional robust in vitro and in vivo studies to optimize the chondrogenesis protocol are required (108).

\section{PBMCs: easy to extract and develop}

PBMCs can be easily extracted from peripheral blood with minimal invasiveness. Recently, PBMCs have been reported to be able to undergo chondrogenic differentiation and have a cartilage generation ability similar to that of MSCs (109). An RCT clinical trial ( $=50)$ investigated the articular cartilage regeneration efficacy of a HA hydrogel laden with PBMCs after arthroscopic subchondral drilling; the results indicated that autologous PBMCs in combination with HA improved the quality of articular cartilage repair (evaluated by histology and MRI scanning) over the same treatment without PBMCs (78). Further studies are desirable to develop the potential of PBMCs for use in the treatment of osteochondral defects; PBMCs can be used as an autologous point-of care treatment to attract native chondrocytes from diseased tissue to aid in cartilage repair (110).

\section{Conclusions and outlook}

In this review, we summarized recent progress regarding the use of stem cell-laden hydrogel biomaterials for cartilage tissue engineering. A summary of the currently available hydrogels and sources of stem cells is illustrated in Figure 3. Due to their injectability, mechanical properties, outstanding biocompatibility, and proper biodegradability, stem cell-laden hydrogels have attracted increasing attention as promising tissue-engineered biomaterials for the repair of full thickness cartilage defects. Various types of stem cells encapsulated in hydrogels have been shown to be able to differentiate into chondrocytes via induction by growth factors and to promote chondrogenesis in vitro and in vivo. Currently, natural polymers and synthetic polymer-based hydrogels are widely used in cartilage engineering. The combination of natural and synthetic polymer hydrogels takes advantages of both types of hydrogel, including their higher biocompatibility and cell viability, widely tunable mechanical properties and proper biodegradability for effective cartilage regeneration, which is promising for future studies and especially clinical trials.

Articular cartilage is a complex functional structure, and several key challenges need to be overcome before fullthickness regeneration of cartilage can be achieved. First, chondrocytes proliferate slowly and easily dedifferentiate into fibroblasts (111), while MSCs laden in a hydrogel may readily become hypertrophic, resulting in the production 


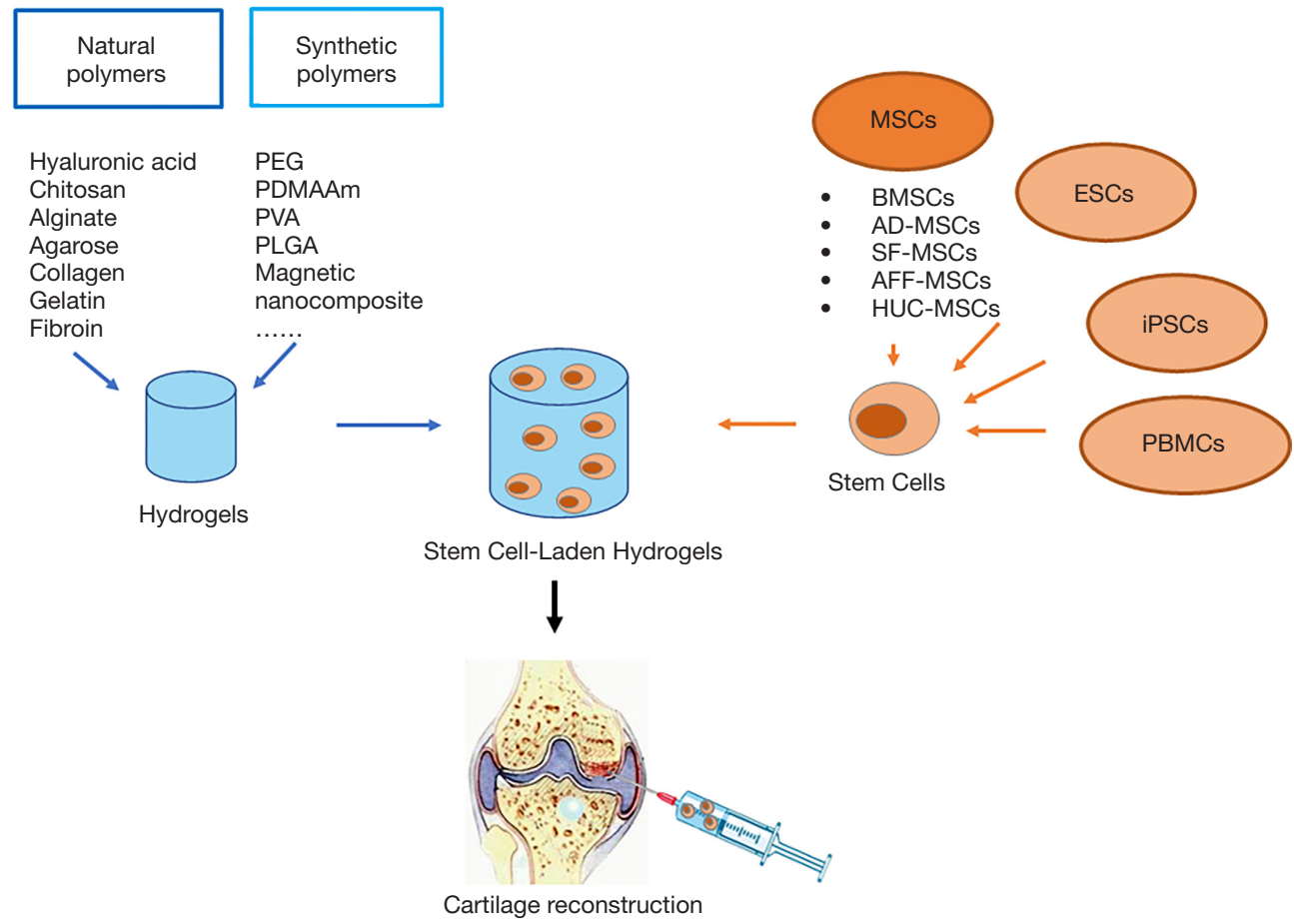

Figure 3 Types of the hydrogels and stem cells used for cartilage tissue engineering. The left part summarizes various types of hydrogels used for cartilage reconstruction, including natural and synthetic polymers. The right part summarizes various sources of stem cells used in cartilage regeneration, including MSCs, ESCs, iPSCs and PBMCs. Due to the extensive use of MSCs, the subgroups of MSCs suitable for cartilage regeneration are also listed. The middle part illustrates the applications of stem cell-laden hydrogels, which are minimally invasive after administration by an injection syringe.

of some bone-like tissues (112). The addition of factors to inhibit endochondral ossification (113) or a preliminary coculture of MSCs and chondrocytes to promote cartilage ECM formation and induce hypertrophy inhibitory factors can be used to overcomes this problem (114). Second, the degradation of hydrogels influences the function of the encapsulated stem cells and the quality of cartilage repair (115). Additional studies are required to develop hydrogels with controllable biodegradability that match the bioactivity of stem cells and the growth rate of cartilage. Third, only hydrogels with a simple composition, such as HA and collagen, have been tested in a clinical setting for cartilage repair, while the alternative, more complex hydrogels have only been investigated at the preclinical stage. Certain barriers to the clinical translation of more complex hydrogel-based constructs remain. Advanced biofabrication technologies, such as $3 \mathrm{D}$ bioprinting, should be investigated in depth to provide better biocompatibility and a lower manufacturing cost, as well as personalized customized regeneration strategies (116), which may highlight the future direction of customized cartilage repair.

\section{Acknowledgments}

Funding: This study was supported by the National Natural Science Foundation of China Youth Science Foundation [81802222]; National Natural Science Foundation of China [81702191]; the Fundamental Research Funds for the Central Universities, South China University of Technology [2018MS70]; the Natural Science Foundation of Guangdong Province [2018A030310694]; the Guangdong Medical Science and Technology Research Foundation [2018114214430383]; the Foundation of Traditional Chinese Medicine of Guangdong Province [20191004]; the scientific Foundation of Guangdong Provincial People's Hospital [2017bp01]; the Outstanding Young Talents Foundation of Guangdong Provincial People's Hospital [KJ012019091]; Program of Science and Technology of Guangzhou [201904010424]; Provincial 


\section{Page 14 of 19}

Science and Technology Major Project of Guangdong [2015B020225007] and the China Postdoctoral Science Foundation [2018M640871].

\section{Footnote}

Reporting Checklist: The authors have completed the Narrative Review reporting checklist. Available at http:// dx.doi.org/10.21037/atm-20-2342

Peer Review File: Available at http://dx.doi.org/10.21037/ atm-20-2342

Conflicts of Interest: All authors have completed the ICMJE uniform disclosure form (available at http://dx.doi. org/10.21037/atm-20-2342). The authors have no conflicts of interest to declare.

Ethical Statement: The authors are accountable for all aspects of the work in ensuring that questions related to the accuracy or integrity of any part of the work are appropriately investigated and resolved. The ethics approval is not required in the present study since it is a review.

Open Access Statement: This is an Open Access article distributed in accordance with the Creative Commons Attribution-NonCommercial-NoDerivs 4.0 International License (CC BY-NC-ND 4.0), which permits the noncommercial replication and distribution of the article with the strict proviso that no changes or edits are made and the original work is properly cited (including links to both the formal publication through the relevant DOI and the license). See: https://creativecommons.org/licenses/by-nc-nd/4.0/.

\section{References}

1. Anandacoomarasamy A, Smith G, Leibman S, et al. Cartilage defects are associated with physical disability in obese adults. Rheumatology (Oxford) 2009;48:1290-3 .

2. Armiento AR, Stoddart MJ, Alini M, et al. Biomaterials for articular cartilage tissue engineering: Learning from biology. Acta Biomater 2018;65:1-20.

3. Galperin A, Oldinski RA, Florczyk SJ, et al. Integrated bilayered scaffold for osteochondral tissue engineering. Adv Healthc Mater 2013;2:872-83.

4. Spakova T, Amrichova J, Plsikova J, et al. A Preliminary Study Comparing Microfracture and Local Adherent Transplantation of Autologous Adipose-Derived Stem
Deng et al. Stem cell and hydrogels for cartilage reconstruction

Cells Followed by Intraarticular Injection of Platelet-Rich Plasma for the Treatment of Chondral Defects in Rabbits. Cartilage 2018;9:410-6.

5. Giannoni P, Pagano A, Maggi E, et al. Autologous chondrocyte implantation (ACI) for aged patients: development of the proper cell expansion conditions for possible therapeutic applications. Osteoarthritis Cartilage 2005;13:589-600.

6. Yang J, Zhang YS, Yue K, et al. Cell-laden hydrogels for osteochondral and cartilage tissue engineering. Acta Biomater 2017;57:1-25.

7. Yue K, Trujillo-de Santiago G, Alvarez MM, et al. Synthesis, properties, and biomedical applications of gelatin methacryloyl (GelMA) hydrogels. Biomaterials 2015;73:254-71.

8. Nuernberger S, Cyran N, Albrecht C, et al. The influence of scaffold architecture on chondrocyte distribution and behavior in matrix-associated chondrocyte transplantation grafts. Biomaterials 2011;32:1032-40.

9. Spiller KL, Maher SA, Lowman AM. Hydrogels for the repair of articular cartilage defects. Tissue Eng Part B Rev 2011;17:281-99.

10. Xu J, Feng Q, Lin S, et al. Injectable stem cell-laden supramolecular hydrogels enhance in situ osteochondral regeneration via the sustained co-delivery of hydrophilic and hydrophobic chondrogenic molecules. Biomaterials 2019;210:51-61.

11. Jooybar E, Abdekhodaie MJ, Alvi M, et al. An injectable platelet lysate-hyaluronic acid hydrogel supports cellular activities and induces chondrogenesis of encapsulated mesenchymal stem cells. Acta Biomater 2019;83:233-44.

12. Xie X, Zhang Q, Zhou T, et al. The Review of Nanomaterials Inducing the Differentiation of Stem Cells into Chondrocyte Phenotypes in Cartilage Tissue Engineering. Curr Stem Cell Res Ther 2018;13:600-7.

13. Vega SL, Kwon MY, Burdick JA. Recent advances in hydrogels for cartilage tissue engineering. Eur Cell Mater 2017;33:59-75.

14. Liu M, Zeng X, Ma C, et al. Injectable hydrogels for cartilage and bone tissue engineering. Bone Res 2017;5:17014.

15. Schütz K, Despang F, Lode A, et al. Cell-laden biphasic scaffolds with anisotropic structure for the regeneration of osteochondral tissue. J Tissue Eng Regen Med 2016;10:404-17.

16. Feng Q, Lin S, Zhang K, et al. Sulfated hyaluronic acid hydrogels with retarded degradation and enhanced growth factor retention promote hMSC chondrogenesis and 
articular cartilage integrity with reduced hypertrophy. Acta Biomater 2017;53:329-42.

17. Zhou Y, Liang K, Zhao S, et al. Photopolymerized maleilated chitosan/methacrylated silk fibroin micro/ nanocomposite hydrogels as potential scaffolds for cartilage tissue engineering. Int J Biol Macromol 2018;108:383-90.

18. Gentile P, Ghione C, Ferreira AM, et al. Alginate-based hydrogels functionalised at the nanoscale using layer-bylayer assembly for potential cartilage repair. Biomater Sci 2017;5:1922-31.

19. Zhu Y, Kong L, Farhadi F, et al. An injectable continuous stratified structurally and functionally biomimetic construct for enhancing osteochondral regeneration. Biomaterials 2019;192:149-58.

20. Parmar PA, St-Pierre JP, Chow LW, et al. Enhanced articular cartilage by human mesenchymal stem cells in enzymatically mediated transiently RGDSfunctionalized collagen-mimetic hydrogels. Acta Biomater 2017;51:75-88.

21. Agas D, Laus F, Lacava G, et al. Thermosensitive hybrid hyaluronan/p(HPMAm-lac)-PEG hydrogels enhance cartilage regeneration in a mouse model of osteoarthritis. J Cell Physiol 2019;234:20013-27.

22. Higa K, Kitamura N, Goto K, et al. Effects of osteochondral defect size on cartilage regeneration using a double-network hydrogel. BMC Musculoskelet Disord 2017;18:210.

23. Yuan F, Ma M, Lu L, et al. Preparation and properties of polyvinyl alcohol (PVA) and hydroxylapatite (HA) hydrogels for cartilage tissue engineering. Cell Mol Biol (Noisy-le-grand) 2017;63:32-5.

24. Knudson CB. Hyaluronan and CD44: strategic players for cell-matrix interactions during chondrogenesis and matrix assembly. Birth Defects Res C Embryo Today 2003;69:174-96.

25. Barbucci R, Lamponi S, Borzacchiello A, et al. Hyaluronic acid hydrogel in the treatment of osteoarthritis. Biomaterials 2002;23:4503-13.

26. Kang ML, Jeong SY, Im GI. Hyaluronic Acid Hydrogel Functionalized with Self-Assembled Micelles of Amphiphilic PEGylated Kartogenin for the Treatment of Osteoarthritis. Tissue Eng Part A 2017;23:630-9.

27. Bian L, Zhai DY, Tous E, et al. Enhanced MSC chondrogenesis following delivery of TGF-beta3 from alginate microspheres within hyaluronic acid hydrogels in vitro and in vivo. Biomaterials 2011;32:6425-34.

28. Toh WS, Lee EH, Guo XM, et al. Cartilage repair using hyaluronan hydrogel-encapsulated human embryonic stem cell-derived chondrogenic cells. Biomaterials 2010;31:6968-80.

29. Unterman SA, Gibson M, Lee JH, et al. Hyaluronic acidbinding scaffold for articular cartilage repair. Tissue Eng Part A 2012;18:2497-506.

30. Nettles DL, Vail TP, Morgan MT, et al. Photocrosslinkable hyaluronan as a scaffold for articular cartilage repair. Ann Biomed Eng 2004;32:391-7.

31. Zhu D, Wang H, Trinh $\mathrm{P}$, et al. Elastin-like proteinhyaluronic acid (ELP-HA) hydrogels with decoupled mechanical and biochemical cues for cartilage regeneration. Biomaterials 2017;127:132-40.

32. Ivanovska J, Zehnder T, Lennert $\mathrm{P}$, et al. Biofabrication of 3D Alginate-Based Hydrogel for Cancer Research: Comparison of Cell Spreading, Viability, and Adhesion Characteristics of Colorectal HCT116 Tumor Cells. Tissue Eng Part C Methods 2016;22:708-15.

33. Chung JY, Song M, Ha CW, et al. Comparison of articular cartilage repair with different hydrogel-human umbilical cord blood-derived mesenchymal stem cell composites in a rat model. Stem Cell Res Ther 2014;5:39.

34. Desai RM, Koshy ST, Hilderbrand SA, et al. Versatile click alginate hydrogels crosslinked via tetrazine-norbornene chemistry. Biomaterials 2015;50:30-7.

35. Critchley S, Cunniffe G, O'Reilly A, et al. Regeneration of Osteochondral Defects Using Developmentally Inspired Cartilaginous Templates. Tissue Eng Part A 2019;25:159-71.

36. Sathy BN, Daly A, Gonzalez-Fernandez T, et al. Hypoxia mimicking hydrogels to regulate the fate of transplanted stem cells. Acta Biomater 2019;88:314-24.

37. Hashimoto T, Suzuki Y, Tanihara M, et al. Development of alginate wound dressings linked with hybrid peptides derived from laminin and elastin. Biomaterials 2004;25:1407-14.

38. Müller M, Ozturk E, Arlov O, et al. Alginate SulfateNanocellulose Bioinks for Cartilage Bioprinting Applications. Ann Biomed Eng 2017;45:210-23.

39. Awad HA, Wickham MQ, Leddy HA, et al. Chondrogenic differentiation of adipose-derived adult stem cells in agarose, alginate, and gelatin scaffolds. Biomaterials 2004;25:3211-22.

40. Bian L, Fong JV, Lima EG, et al. Dynamic mechanical loading enhances functional properties of tissueengineered cartilage using mature canine chondrocytes. Tissue Eng Part A 2010;16:1781-90.

41. Sheehy EJ, Mesallati T, Vinardell T, et al. Engineering cartilage or endochondral bone: a comparison of 


\section{Page 16 of 19}

different naturally derived hydrogels. Acta Biomater 2015;13:245-53.

42. Román J, Cabanas MV, Pena J, et al. An optimized betatricalcium phosphate and agarose scaffold fabrication technique. J Biomed Mater Res A 2008;84:99-107.

43. Miao Z, Lu Z, Wu H, et al. Collagen, agarose, alginate, and Matrigel hydrogels as cell substrates for culture of chondrocytes in vitro: A comparative study. J Cell Biochem 2018;119:7924-33.

44. Mauck RL, Yuan X, Tuan RS. Chondrogenic differentiation and functional maturation of bovine mesenchymal stem cells in long-term agarose culture. Osteoarthritis Cartilage 2006;14:179-89.

45. Younes I, Rinaudo M. Chitin and chitosan preparation from marine sources. Structure, properties and applications. Mar Drugs 2015;13:1133-74.

46. Jin R, Moreira Teixeira LS, Dijkstra PJ, et al. Injectable chitosan-based hydrogels for cartilage tissue engineering. Biomaterials 2009;30:2544-51.

47. Choi B, Kim S, Lin B, et al. Cartilaginous extracellular matrix-modified chitosan hydrogels for cartilage tissue engineering. ACS Appl Mater Interfaces 2014;6:20110-21.

48. Kamoun EA. N-succinyl chitosan-dialdehyde starch hybrid hydrogels for biomedical applications. J Adv Res 2016;7:69-77.

49. Levingstone TJ, Matsiko A, Dickson GR, et al. A biomimetic multi-layered collagen-based scaffold for osteochondral repair. Acta Biomater 2014;10:1996-2004.

50. Bosnakovski D, Mizuno M, Kim G, et al. Chondrogenic differentiation of bovine bone marrow mesenchymal stem cells (MSCs) in different hydrogels: influence of collagen type II extracellular matrix on MSC chondrogenesis. Biotechnol Bioeng 2006;93:1152-63.

51. Li YY, Cheng HW, Cheung KM, et al. Mesenchymal stem cell-collagen microspheres for articular cartilage repair: cell density and differentiation status. Acta Biomater 2014;10:1919-29.

52. Sakai S, Hirose K, Taguchi K, et al. An injectable, in situ enzymatically gellable, gelatin derivative for drug delivery and tissue engineering. Biomaterials 2009;30:3371-7.

53. Mouser VH, Melchels FP, Visser J, et al. Yield stress determines bioprintability of hydrogels based on gelatinmethacryloyl and gellan gum for cartilage bioprinting. Biofabrication 2016;8:035003.

54. Yodmuang S, McNamara SL, Nover AB, et al. Silk microfiber-reinforced silk hydrogel composites for functional cartilage tissue repair. Acta Biomater 2015;11:27-36.

\section{Deng et al. Stem cell and hydrogels for cartilage reconstruction}

55. Munoz-Pinto DJ, McMahon RE, Kanzelberger MA, et al. Inorganic-organic hybrid scaffolds for osteochondral regeneration. J Biomed Mater Res A 2010;94:112-21.

56. Sharma B, Fermanian S, Gibson M, et al. Human cartilage repair with a photoreactive adhesive-hydrogel composite.

Sci Transl Med 2013;5:167ra6.

57. Goldshmid R, Cohen S, Shachaf Y, et al. Steric Interference of Adhesion Supports In-Vitro Chondrogenesis of Mesenchymal Stem Cells on Hydrogels for Cartilage Repair. Sci Rep 2015;5:12607.

58. Wang W, Li B, Yang J, et al. The restoration of fullthickness cartilage defects with BMSCs and TGFbeta 1 loaded PLGA/fibrin gel constructs. Biomaterials 2010;31:8964-73.

59. Nyoung Heo D, Kim HJ, Lee D, et al. Comparison of polysaccharides in articular cartilage regeneration associated with chondrogenic and autophagy-related gene expression. Int J Biol Macromol 2019:S01418130(19)31887-2.

60. Wei X, Yang X, Han ZP, et al. Mesenchymal stem cells: a new trend for cell therapy. Acta Pharmacol Sin 2013;34:747-54.

61. Krampera M, Pizzolo G, Aprili G, et al. Mesenchymal stem cells for bone, cartilage, tendon and skeletal muscle repair. Bone 2006;39:678-83.

62. Hass R, Kasper C, Bohm S, et al. Different populations and sources of human mesenchymal stem cells (MSC): A comparison of adult and neonatal tissue-derived MSC. Cell Commun Signal 2011;9:12.

63. Wu KC, Chang YH, Liu HW, et al. Transplanting human umbilical cord mesenchymal stem cells and hyaluronate hydrogel repairs cartilage of osteoarthritis in the minipig model. Ci Ji Yi Xue Za Zhi 2019;31:11-9.

64. Vayas R, Reyes R, Arnau MR, et al. Injectable Scaffold for Bone Marrow Stem Cells and Bone Morphogenetic Protein-2 to Repair Cartilage. Cartilage 2019. [Epub ahead of print].

65. Pipino G, Risitano S, Alviano F, et al. Microfractures and hydrogel scaffolds in the treatment of osteochondral knee defects: A clinical and histological evaluation. J Clin Orthop Trauma 2019;10:67-75.

66. Pascual-Garrido C, Aisenbrey EA, Rodriguez-Fontan F, et al. Photopolymerizable Injectable Cartilage Mimetic Hydrogel for the Treatment of Focal Chondral Lesions: A Proof of Concept Study in a Rabbit Animal Model. Am J Sports Med 2019;47:212-21.

67. Park YB, Ha CW, Kim JA, et al. Comparison of Undifferentiated Versus Chondrogenic Predifferentiated 
Mesenchymal Stem Cells Derived From Human Umbilical Cord Blood for Cartilage Repair in a Rat Model. Am J Sports Med 2019;47:451-61.

68. Jia Z, Zhu F, Li X, et al. Repair of osteochondral defects using injectable chitosan-based hydrogel encapsulated synovial fluid-derived mesenchymal stem cells in a rabbit model. Mater Sci Eng C Mater Biol Appl 2019;99:541-51.

69. Uto S, Nishizawa S, Hikita A, et al. Application of induced pluripotent stem cells for cartilage regeneration in CLAWN miniature pig osteochondral replacement model. Regen Ther 2018;9:58-70.

70. Lv X, He J, Zhang X, et al. Comparative Efficacy of Autologous Stromal Vascular Fraction and Autologous Adipose-Derived Mesenchymal Stem Cells Combined With Hyaluronic Acid for the Treatment of Sheep Osteoarthritis. Cell Transplant 2018;27:1111-25.

71. Li J, Huang Y, Song J, et al. Cartilage regeneration using arthroscopic flushing fluid-derived mesenchymal stem cells encapsulated in a one-step rapid cross-linked hydrogel. Acta Biomater 2018;79:202-15.

72. Feng C, Luo X, He N, et al. Efficacy and Persistence of Allogeneic Adipose-Derived Mesenchymal Stem Cells Combined with Hyaluronic Acid in Osteoarthritis After Intra-articular Injection in a Sheep Model. Tissue Eng Part A 2018;24:219-33.

73. Desando G, Bartolotti I, Cavallo C, et al. Short-Term Homing of Hyaluronan-Primed Cells: Therapeutic Implications for Osteoarthritis Treatment. Tissue Eng Part C Methods 2018;24:121-33.

74. Choi SM, Lee KM, Ryu SB, et al. Enhanced articular cartilage regeneration with SIRT1-activated MSCs using gelatin-based hydrogel. Cell Death Dis 2018;9:866.

75. Kim SJ, Kim JE, Kim SH, et al. Therapeutic effects of neuropeptide substance $\mathrm{P}$ coupled with self-assembled peptide nanofibers on the progression of osteoarthritis in a rat model. Biomaterials 2016;74:119-30.

76. Chiang ER, Ma HL, Wang JP, et al. Allogeneic Mesenchymal Stem Cells in Combination with Hyaluronic Acid for the Treatment of Osteoarthritis in Rabbits. PLoS One 2016;11:e0149835.

77. Kim JE, Lee SM, Kim SH, et al. Effect of selfassembled peptide-mesenchymal stem cell complex on the progression of osteoarthritis in a rat model. Int $\mathrm{J}$ Nanomedicine 2014;9 Suppl 1:141-57.

78. Saw KY, Anz A, Siew-Yoke Jee C, et al. Articular cartilage regeneration with autologous peripheral blood stem cells versus hyaluronic acid: a randomized controlled trial. Arthroscopy 2013;29:684-94.
79. Suhaeb AM, Naveen S, Mansor A, et al. Hyaluronic acid with or without bone marrow derived-mesenchymal stem cells improves osteoarthritic knee changes in rat model: a preliminary report. Indian J Exp Biol 2012;50:383-90.

80. Sato M, Uchida K, Nakajima H, et al. Direct transplantation of mesenchymal stem cells into the knee joints of Hartley strain guinea pigs with spontaneous osteoarthritis. Arthritis Res Ther 2012;14:R31.

81. Lee KB, Wang VT, Chan YH, et al. A novel, minimallyinvasive technique of cartilage repair in the human knee using arthroscopic microfracture and injections of mesenchymal stem cells and hyaluronic acid--a prospective comparative study on safety and short-term efficacy. Ann Acad Med Singapore 2012;41:511-7.

82. Kim SS, Kang MS, Lee KY, et al. Therapeutic effects of mesenchymal stem cells and hyaluronic Acid injection on osteochondral defects in rabbits' knees. Knee Surg Relat Res 2012;24:164-72.

83. Mokbel AN, El Tookhy OS, Shamaa AA, et al. Homing and reparative effect of intra-articular injection of autologus mesenchymal stem cells in osteoarthritic animal model. BMC Musculoskelet Disord 2011;12:259.

84. McIlwraith CW, Frisbie DD, Rodkey WG, et al. Evaluation of intra-articular mesenchymal stem cells to augment healing of microfractured chondral defects. Arthroscopy 2011;27:1552-61.

85. Saw KY, Hussin P, Loke SC, et al. Articular cartilage regeneration with autologous marrow aspirate and hyaluronic Acid: an experimental study in a goat model. Arthroscopy 2009;25:1391-400.

86. Lee KB, Hui JH, Song IC, et al. Injectable mesenchymal stem cell therapy for large cartilage defects--a porcine model. Stem Cells 2007;25:2964-71.

87. Murphy JM, Fink DJ, Hunziker EB, et al. Stem cell therapy in a caprine model of osteoarthritis. Arthritis Rheum 2003;48:3464-74.

88. Lu CH, Yeh TS, Yeh CL, et al. Regenerating cartilages by engineered ASCs: prolonged TGF-beta3/BMP-6 expression improved articular cartilage formation and restored zonal structure. Mol Ther 2014;22:186-95.

89. Deng Y, Sun AX, Overholt KJ, et al. Enhancing chondrogenesis and mechanical strength retention in physiologically relevant hydrogels with incorporation of hyaluronic acid and direct loading of TGF-beta. Acta Biomater 2019;83:167-76.

90. Kwon MY, Vega SL, Gramlich WM, et al. Dose and Timing of N-Cadherin Mimetic Peptides Regulate MSC Chondrogenesis within Hydrogels. Adv Healthc Mater 


\section{Page 18 of 19}

2018;7:e1701199.

91. Wang Z, Li K, Sun H, et al. Icariin promotes stable chondrogenic differentiation of bone marrow mesenchymal stem cells in selfassembling peptide nanofiber hydrogel scaffolds. Mol Med Rep 2018;17:8237-43.

92. Liu C, Li T, Yang Z, et al. Kartogenin Enhanced Chondrogenesis in Cocultures of Chondrocytes and Bone Mesenchymal Stem Cells. Tissue Eng Part A 2018;24:990-1000.

93. Huang J, Liang Y, Jia Z, et al. Development of Magnetic Nanocomposite Hydrogel with Potential Cartilage Tissue Engineering. ACS Omega 2018;3:6182-9.

94. Amann E, Wolff P, Breel E, et al. Hyaluronic acid facilitates chondrogenesis and matrix deposition of human adipose derived mesenchymal stem cells and human chondrocytes co-cultures. Acta Biomater 2017;52:130-44.

95. Liang Y, Idrees E, Szojka ARA, et al. Chondrogenic differentiation of synovial fluid mesenchymal stem cells on human meniscus-derived decellularized matrix requires exogenous growth factors. Acta Biomater 2018;80:131-43.

96. Zayed M, Caniglia C, Misk N, et al. Donor-Matched Comparison of Chondrogenic Potential of Equine Bone Marrow- and Synovial Fluid-Derived Mesenchymal Stem Cells: Implications for Cartilage Tissue Regeneration. Front Vet Sci 2017;3:121.

97. Zayed M, Newby S, Misk N, et al. Xenogenic Implantation of Equine Synovial Fluid-Derived Mesenchymal Stem Cells Leads to Articular Cartilage Regeneration. Stem Cells Int 2018;2018:1073705.

98. Neybecker P, Henrionnet C, Pape E, et al. In vitro and in vivo potentialities for cartilage repair from human advanced knee osteoarthritis synovial fluid-derived mesenchymal stem cells. Stem Cell Res Ther 2018;9:329.

99. Park YB, Ha CW, Lee CH, et al. Cartilage Regeneration in Osteoarthritic Patients by a Composite of Allogeneic Umbilical Cord Blood-Derived Mesenchymal Stem Cells and Hyaluronate Hydrogel: Results from a Clinical Trial for Safety and Proof-of-Concept with 7 Years of Extended Follow-Up. Stem Cells Transl Med 2017;6:613-21.

100.Wang J, Rao S, Chu J, et al. A protein interaction network for pluripotency of embryonic stem cells. Nature 2006;444:364-8.

101.Hwang NS, Varghese S, Zhang Z, et al. Chondrogenic differentiation of human embryonic stem cell-derived cells in arginine-glycine-aspartate-modified hydrogels. Tissue Eng 2006;12:2695-706.
Deng et al. Stem cell and hydrogels for cartilage reconstruction

102.Zhang S, Chu WC, Lai RC, et al. Exosomes derived from human embryonic mesenchymal stem cells promote osteochondral regeneration. Osteoarthritis Cartilage 2016;24:2135-40.

103. Wang Y, Yu D, Liu Z, et al. Exosomes from embryonic mesenchymal stem cells alleviate osteoarthritis through balancing synthesis and degradation of cartilage extracellular matrix. Stem Cell Res Ther 2017;8:189.

104. Murry CE, Keller G. Differentiation of embryonic stem cells to clinically relevant populations: lessons from embryonic development. Cell 2008;132:661-80.

105. Okita K, Ichisaka T, Yamanaka S. Generation of germlinecompetent induced pluripotent stem cells. Nature 2007;448:313-7.

106. Ko JY, Kim KI, Park S, et al. In vitro chondrogenesis and in vivo repair of osteochondral defect with human induced pluripotent stem cells. Biomaterials 2014;35:3571-81.

107.He P, Fu J, Wang DA. Murine pluripotent stem cells derived scaffold-free cartilage grafts from a micro-cavitary hydrogel platform. Acta Biomater 2016;35:87-97.

108. Castro-Viñuelas R, Sanjurjo-Rodriguez C, Pineiro-Ramil $\mathrm{M}$, et al. Induced pluripotent stem cells for cartilage repair: current status and future perspectives. Eur Cell Mater 2018;36:96-109.

109. Lam J, Lu S, Meretoja VV, et al. Generation of osteochondral tissue constructs with chondrogenically and osteogenically predifferentiated mesenchymal stem cells encapsulated in bilayered hydrogels. Acta Biomater 2014;10:1112-23.

110. Hopper N, Henson F, Brooks R, et al. Peripheral blood derived mononuclear cells enhance osteoarthritic human chondrocyte migration. Arthritis Res Ther 2015;17:199.

111. Nukavarapu SP, Dorcemus DL. Osteochondral tissue engineering: current strategies and challenges. Biotechnol Adv 2013;31:706-21.

112. Yang $\mathrm{W}$, Yang F, Wang $\mathrm{Y}$, et al. In vivo bone generation via the endochondral pathway on three-dimensional electrospun fibers. Acta Biomater 2013;9:4505-12.

113. Nagai T, Sato M, Kutsuna T, et al. Intravenous administration of anti-vascular endothelial growth factor humanized monoclonal antibody bevacizumab improves articular cartilage repair. Arthritis Res Ther 2010;12:R178.

114. Cooke ME, Allon AA, Cheng T, et al. Structured threedimensional co-culture of mesenchymal stem cells with chondrocytes promotes chondrogenic differentiation without hypertrophy. Osteoarthritis Cartilage 
2011;19:1210-8.

115. Chung C, Beecham M, Mauck RL, et al. The influence of degradation characteristics of hyaluronic acid hydrogels on in vitro neocartilage formation by mesenchymal stem cells.
Biomaterials 2009;30:4287-96.

116.Levato R, Visser J, Planell JA, et al. Biofabrication of tissue constructs by $3 \mathrm{D}$ bioprinting of cell-laden microcarriers. Biofabrication 2014;6:035020.

Cite this article as: Deng Z, Jin J, Wang S, Qi F, Chen X, Liu C, Li Y, Ma Y, Lyu F, Zheng Q. Narrative review of the choices of stem cell sources and hydrogels for cartilage tissue engineering. Ann Transl Med 2020;8(23):1598. doi: 10.21037/ atm-20-2342 